\title{
Clinical Outcomes of Antithrombotic Strategies for Patients with Atrial Fibrillation After Percutaneous Coronary Intervention Evidence from a Network Meta-Analysis
}

\author{
Xiaofei Gao, ${ }^{1,2}$ MSc, Zhen Ge, ${ }^{1}$ MD, Xiangquan Kong, ${ }^{1}$ PhD, Zhimei Wang, ${ }^{1}$ MSc, \\ Guangfeng Zuo, ${ }^{1}$ MSc, Feng Wang, ${ }^{1}$ MSc, Shaoliang Chen, ${ }^{1,2}$ MD and Junjie Zhang, ${ }^{1,2}$ MD
}

\begin{abstract}
Summary
Antithrombotic strategies for patients with atrial fibrillation (AF) undergoing percutaneous coronary intervention (PCI) remain challenging. This study aims to explore the best antithrombotic strategy for AF patients after PCI based on a network meta-analysis. This study was registered in PROSPERO (CRD42018093928). The PubMed, Cochrane, and EMBASE databases were searched to identify clinical trials concerning antithrombotic therapy for AF patients with PCI from inception to April 2018. Pairwise and network meta-analysis were conducted to compare clinical outcomes of different antithrombotic therapy. The primary endpoint was major bleeding. Fifteen studies including 16,382 patients were identified with follow-up ranging from 3 to 12 months. Non-vitamin K oral anticoagulants (NOAC) plus $\mathrm{P}_{2} \mathrm{Y}_{12}$ inhibitor ranked first with a reduced risk of major bleeding compared with vitamin $\mathrm{K}$ antagonist (VKA) plus dual antiplatelet therapy (OR: 0.57, 95\% CI: 0.43-0.75) but with no significant difference compared with VKA plus single platelet therapy (OR: 0.85, 95\% CI: 0.621.16). Similar thrombotic events were evident among these groups. Subgroup analysis showed that VKA plus aspirin exhibited a similar risk of major bleeding compared with VKA plus clopidogrel (OR: 0.94, 95\% CI: 0.73-1.23) but was associated with increased risks of ischaemic stroke (OR: 2.10, 95\% CI: 1.33-3.32) and allcause death (OR: 1.77, 95\% CI: 1.15-2.74) versus VKA plus clopidogrel. In AF patients undergoing PCI, NOAC plus $\mathrm{P}_{2} \mathrm{Y}_{12}$ inhibitor and VKA plus clopidogrel, but not VKA plus aspirin, were associated with reduced risk of major bleeding compared with the recommended VKA-based triple therapy, while thrombotic events were similar among these treatments.
\end{abstract}

Key words: Oral anticoagulant, Antiplatelet therapy

(Int Heart J 2019; 60: 546-553)

A ntithrombotic strategies for patients with atrial fibrillation (AF) after percutaneous coronary intervention $(\mathrm{PCI})$ remain challenging with poor clinical outcomes. ${ }^{1,2}$ It has been confirmed that dual antiplatelet therapy (DAPT), including aspirin and a P2 $\mathrm{Y}_{12}$ inhibitor, is not a good choice for these patients due to increased risk of ischaemic stroke and embolism complications. $^{3,4)}$ Traditional triple therapy (vitamin $\mathrm{K}$ antagonist [VKA] + DAPT), which is recommended by current guidelines, ${ }^{5,6)}$ is associated with reduced ischaemic events but at the cost of the unacceptable risk of major bleeding. ${ }^{3,47)}$ Hence, VKA plus single antiplatelet therapy (SAPT), such as aspirin or clopidogrel, is also recommended to reduce the bleeding risk. ${ }^{5,6}$ Notably, two randomized controlled trials $(\mathrm{RCT})^{8,9)}$ have been published recently to demonstrate that nonvitamin $\mathrm{K}$ oral anticoagu- lant (NOAC) with a $\mathrm{P}_{2} \mathrm{Y}_{12}$ inhibitor was associated with a reduced risk of bleeding without an increased risk of thromboembolic events compared with VKA-based triple therapy. Recent current guidelines ${ }^{5,6)}$ recommend 3 strategies, namely, VKA + DAPT, VKA + SAPT, and NOAC + $\mathrm{P} \mathrm{Y}_{12}$ inhibitor, for AF patients undergoing PCI. However, direct head-to-head comparisons of VKA + Aspirin, VKA + Clopidogrel, and NOAC + P2Y $Y_{12}$ inhibitor have not been performed, and we do not know which strategy should be the first choice for patients with AF receiving stents. Therefore, the present study aims to explore the best antithrombotic strategy for AF patients undergoing PCI using a network meta-analysis.

From the ${ }^{1}$ Department of Cardiology, Nanjing First Hospital, Nanjing Medical University, Nanjing, China and ${ }^{2}$ Department of Cardiology, Nanjing Heart Centre, Nanjing, China.

This study was support by the National Science Foundation of China (NSFC 81770342), Nanjing Health and Family Planning Commission (YKK16124), and Nanjing Municipal Commission of Science \& Technology (201715026). There were no relationships with industry. The funding agency did not have a role in the design of the study or the collection, analysis, and interpretation of data or in writing the manuscript.

Address for correspondence: Junjie Zhang, MD, Department of Cardiology, Nanjing First Hospital, Nanjing Medical University, No. 68 Changle Road, 210006 Nanjing, China. E-mail: jameszll@163.com

Received for publication July 31, 2018. Revised and accepted October 11, 2018

Released in advance online on J-STAGE May 17, 2019.

doi: 10.1536/ihj.18-464

All rights reserved by the International Heart Journal Association. 


\section{Methods}

Literature search: RCTs and observational studies on antithrombotic strategies for AF patients receiving coronary intervention were acquired by searching PubMed, the Cochrane database, EMBASE, and ClinicalTrials.gov from inception to April 2018. The following combination of key words was used to search all relevant studies: "AF", "PCI", "coronary stenting", "oral anticoagulants (OAC)", "warfarin", "NOAC", "dabigatran", "rivaroxaban", "apixaban", "edoxaban", "aspirin", "clopidogrel", "P2 $\mathrm{Y}_{12}$ inhibitor", and "DAPT". We also further screened references from selected studies and reviews.

Inclusion and exclusion criteria: The inclusion criteria were as follows: (1) patients taking OAC after PCI with indications for OAC and DAPT; (2) clinical outcomes comparing different antithrombotic therapies; and (3) $\geq 3$ months of clinical follow-up. The exclusion criteria were as follows: (1) non-English-language studies; (2) antithrombotic therapy for AF patients or AF patients with stable angina; (3) studies about DAPT for AF and PCI were excluded given the definite increased risk of thromboembolic events; (4) ticagrelor and prasugrel were excluded given the limited number of studies and increased risk of bleeding when combined with OAC; (5) other antithrombotic strategies (NOAC + DAPT, or NOAC + Aspirin) were excluded due to small sample sizes; and (6) studies with duplicate publications or those using the same samples.

Data extraction, quality assessment, and study endpoints: Two investigators (GXF and GZ) independently reviewed all relevant articles to assess study eligibility using standardized data forms. Conflicts were resolved by a third investigator (KXQ). The quality of the included studies was assessed using the Newcastle-Ottawa scale for observational studies and Cochrane Collaboration tool for RCTs.

The primary endpoint of this network meta-analysis was major bleeding. The secondary endpoints included major adverse cardiovascular events (MACE) based on the definition of individual study, all-cause death, ischaemic stroke, stent thrombosis, and myocardial infarction (MI). The rates of ischaemic stroke and all-cause death were replaced by stroke events and cardiac death if no relevant data existed.

Statistical analysis: The present meta-analysis was conducted based on the Preferred Reporting Items for Systematic Reviews and Meta-analysis (PRISMA) network meta-analysis checklist. First, we performed the standard pairwise meta-analysis using STATA software 14.0 (StataCorp, College Station, TX, USA) to compare the safety and efficacy of triple therapy (VKA + DAPT) and dual therapy (VKA + SAPT and NOAC + P2 $\mathrm{Y}_{12}$ inhibitor). The heterogeneity of all included studies was assessed using the $I^{2}$ statistic and Cochrane $Q$ test with $I^{2} \geq 50 \%$ and/ or $Q$ test $P<0.10$ indicating the presence of high heterogeneity. If high heterogeneity was noted among studies, the random-effects model was used. Otherwise, the fixedeffects model was performed. The pooled effect of treatments was presented as odds ratio (OR) and 95\% confidence interval (CI). Egger's test was used to evaluate the publication bias. Sensitivity analysis was also performed to assess the stability of the overall effects with exclusion of one study at a time.

We conducted network meta-analysis to compare the effects of 3 strategies (VKA + DAPT, VKA + SAPT, and $\mathrm{NOAC}+\mathrm{P}_{2} \mathrm{Y}_{12}$ inhibitor) using a network family of commands in STATA software 14.0. ${ }^{10,11)}$ The network plot was a visual image with nodes representing the different strategies being compared and edges representing the available direct comparisons. Comparison-adjusted funnel plots were used to assess the bias of small studies. The presence of inconsistency in the networks of antithrombotic strategies was explored using a loop-specific approach with an inconsistency factor and its CI for each loop. Ranking of treatments in networks using probabilities was conducted with the estimated surface under the cumulative ranking curve (SUCRA) and rankograms (line plots of the probabilities versus ranks) for different antithrombotic strategies. We also performed subgroup analysis based on the type of SAPT to compare 4 strategies (VKA + DAPT, $\mathrm{VKA}+$ Aspirin, VKA + Clopidogrel, and NOAC + $\mathrm{P}_{2} \mathrm{Y}_{12}$ inhibitor) with similar statistical methods.

This study was registered in PROSPERO, number CRD42018093928.

\section{Results}

Eligible studies and patient characteristics: A total of 15 studies $^{8,9,12-24)}$ with 16,382 patients were included in the present study from 243 initial citations (Supplemental Figure 1). The baseline characteristics of the included studies are summarized in Table I and Supplemental Table I. Of these 15 studies, 4 were RCTs, ${ }^{8,9,14,15)}$ and the remaining 11 were observational studies. It was difficult to evaluate the bias risk due to the absence of a detailed description of the methodology employed for observational studies. The median study follow-up period was 12 months (range, 3 to 12 months). Detailed definitions of major bleeding and MACE are provided in Supplemental Table II.

Pairwise meta-analysis of triple therapy and dual therapy: Detailed results of pairwise meta-analysis are presented in Supplemental Figure 2. Briefly, VKA-based triple therapy was associated with a significantly increased incidence of major bleeding (OR: 1.54, 95\% CI: 1.35 1.76, $P<0.001$ ) compared with dual therapy (VKA/ $\mathrm{NOAC}+\mathrm{SAPT}$ ), and no significant heterogeneity or publication bias was identified $\left(I^{2}=0 \%, P=0.783\right.$; Egger test $P=0.753)$. The risks of MACE, ischaemic stroke, allcause mortality, stent thrombosis, and MI did not significantly differ between triple therapy and dual therapy.

Network meta-analysis of VKA + DAPT, VKA + SAPT, and NOAC + P2Y 12 inhibitor: The network of eligible comparisons for the primary outcomes (major bleeding) is presented in Figure 1A. The contribution plot for major bleeding is presented in Supplemental Figure 3. $\mathrm{NOAC}+\mathrm{P}_{2} \mathrm{Y}_{12}$ inhibitor ranked first (Table II and Figure 2) with a reduced risk of major bleeding compared with VKA + DAPT (OR: 0.57, 95\% CI: 0.43-0.75), however, there was no significant difference compared with VKA + SAPT (OR: 0.85, 95\% CI: 0.62-1.16). We also noted no significant differences in MACE, ischaemic stroke, all- 
Table I. Baseline Characteristics of Included Studies

\begin{tabular}{|c|c|c|c|c|c|c|c|}
\hline Study & Year & Study design & $\begin{array}{l}\text { Sample size } \\
\text { (TT/DT) }\end{array}$ & TT & DT & DT in detail & $\begin{array}{c}\text { Follow-up } \\
\text { (months) }\end{array}$ \\
\hline Nguyen, et al. & 2007 & $\begin{array}{c}\text { Multicenter, retrospective } \\
\text { observation }\end{array}$ & $580 / 220$ & $\begin{array}{l}\text { VKA + } \\
\text { DAPT }\end{array}$ & $\begin{array}{l}\text { VKA + } \\
\text { SAPT }\end{array}$ & $\begin{array}{c}\text { VKA + Aspirin }(48.6 \%) / \\
\text { VKA + Clopidogrel }(51.4 \%)\end{array}$ & 6 \\
\hline Karjalainen, et al. & 2007 & $\begin{array}{c}\text { Multicenter, retrospective } \\
\text { observation }\end{array}$ & $106 / 78$ & $\begin{array}{l}\text { VKA + } \\
\text { DAPT }\end{array}$ & $\begin{array}{l}\text { VKA + } \\
\text { SAPT }\end{array}$ & $\begin{array}{c}\text { VKA + Aspirin (42.3\%) / } \\
\text { VKA + Clopidogrel }(56.7 \%)\end{array}$ & 12 \\
\hline MUSICA & 2009 & $\begin{array}{c}\text { Multicenter, prospective } \\
\text { observation }\end{array}$ & $278 / 46$ & $\begin{array}{l}\text { VKA + } \\
\text { DAPT }\end{array}$ & $\begin{array}{l}\text { VKA + } \\
\text { SAPT }\end{array}$ & $\mathrm{VKA}+\mathrm{SAPT}$ & 6 \\
\hline Gao, et al. & 2009 & $\begin{array}{l}\text { Single-center, prospective } \\
\text { observation }\end{array}$ & $142 / 125$ & $\begin{array}{l}\text { VKA + } \\
\text { DAPT }\end{array}$ & $\begin{array}{l}\text { VKA + } \\
\text { SAPT }\end{array}$ & $\begin{array}{c}\text { VKA + Aspirin }(12.8 \%) / \\
\text { VKA + Clopidogrel }(87.2 \%)\end{array}$ & 12 \\
\hline Persson, et al. & 2011 & $\begin{array}{c}\text { Multicenter, prospective } \\
\text { observation }\end{array}$ & $404 / 565$ & $\begin{array}{l}\text { VKA + } \\
\text { DAPT }\end{array}$ & $\begin{array}{l}\text { VKA }+ \\
\text { SAPT }\end{array}$ & $\begin{array}{c}\text { VKA + Aspirin (12.8\%) / } \\
\text { VKA + Clopidogrel }(87.2 \%)\end{array}$ & 12 \\
\hline REAL & 2012 & $\begin{array}{c}\text { Multicenter, prospective } \\
\text { observation }\end{array}$ & $205 / 111$ & $\begin{array}{l}\text { VKA + } \\
\text { DAPT }\end{array}$ & $\begin{array}{l}\text { VKA + } \\
\text { SAPT }\end{array}$ & $\mathrm{VKA}+$ Aspirin & 12 \\
\hline Lamberts, et al. & 2013 & $\begin{array}{c}\text { Multicenter, prospective } \\
\text { observation }\end{array}$ & $1896 / 2052$ & $\begin{array}{l}\text { VKA + } \\
\text { DAPT }\end{array}$ & $\begin{array}{l}\text { VKA + } \\
\text { SAPT }\end{array}$ & $\begin{array}{c}\text { VKA + Clopidogrel (73\%) / } \\
\text { VKA + Aspirin }(27 \%)\end{array}$ & 12 \\
\hline WOEST & 2013 & $\mathrm{RCT}$ & $284 / 279$ & $\begin{array}{l}\text { VKA + } \\
\text { DAPT }\end{array}$ & $\begin{array}{l}\text { VKA + } \\
\text { SAPT }\end{array}$ & VKA + Clopidogrel & 12 \\
\hline AFCAS & 2014 & $\begin{array}{c}\text { Multicenter, prospective } \\
\text { observation }\end{array}$ & $679 / 73$ & $\begin{array}{l}\text { VKA + } \\
\text { DAPT }\end{array}$ & $\begin{array}{l}\text { VKA + } \\
\text { SAPT }\end{array}$ & VKA + Clopidogrel & 12 \\
\hline ISAR-TRIPLE & 2015 & $\mathrm{RCT}$ & $307 / 307$ & $\begin{array}{l}\text { VKA }+ \\
\text { DAPT }\end{array}$ & $\begin{array}{l}\text { VKA + } \\
\text { SAPT }\end{array}$ & VKA + Aspirin & 9 \\
\hline Vecchis, et al. & 2016 & $\begin{array}{c}\text { Single-center, retrospective } \\
\text { observation }\end{array}$ & $48 / 31$ & $\begin{array}{l}\text { VKA }+ \\
\text { DAPT }\end{array}$ & $\begin{array}{l}\text { VKA }+ \\
\text { SAPT }\end{array}$ & VKA + Aspirin/ VKA + Clopidogrel & 12 \\
\hline PIONEER AF-PCI & 2016 & $\mathrm{RCT}$ & $706 / 709$ & $\begin{array}{l}\text { VKA + } \\
\text { DAPT }\end{array}$ & $\begin{array}{l}\mathrm{NOAC}+ \\
\text { SAPT }\end{array}$ & Rivaroxaban $15 \mathrm{mg}+\mathrm{P} 2 \mathrm{Y} 12 \mathrm{i}$ & 12 \\
\hline ORBIT-AF & 2016 & $\begin{array}{c}\text { Multicenter, prospective } \\
\text { observation }\end{array}$ & $155 / 1468$ & $\begin{array}{l}\text { VKA + } \\
\text { DAPT }\end{array}$ & $\begin{array}{l}\text { VKA + } \\
\text { SAPT }\end{array}$ & $\begin{array}{l}\text { OAC (VKA 94\%, dabigatran 6\%) + } \\
\text { SAPT (aspirin 90\%, clopidogrel 10\%) }\end{array}$ & 12 \\
\hline RE-DUAL PCI & 2017 & $\mathrm{RCT}$ & $\begin{array}{l}981 / 981 \\
764 / 763\end{array}$ & $\begin{array}{l}\text { VKA + } \\
\text { DAPT }\end{array}$ & $\begin{array}{l}\text { NOAC }+ \\
\text { SAPT }\end{array}$ & $\begin{array}{l}\text { Dabigatran } 110 \mathrm{mg}+\mathrm{P} 2 \mathrm{Y} 12 \mathrm{i} \\
\text { Dabigatran } 150 \mathrm{mg}+\mathrm{P} 2 \mathrm{Y} 12 \mathrm{i}\end{array}$ & 12 \\
\hline Batra, et al. & 2018 & $\begin{array}{c}\text { Multicenter, prospective } \\
\text { observation }\end{array}$ & $1153 / 650$ & $\begin{array}{l}\text { VKA }+ \\
\text { DAPT }\end{array}$ & $\begin{array}{l}\text { VKA + } \\
\text { SAPT }\end{array}$ & $\begin{array}{c}\text { VKA + Aspirin (20.6\%) / } \\
\text { VKA + Clopidogrel }(79.4 \%)\end{array}$ & 3 \\
\hline
\end{tabular}

RCT indicates randomized controlled trial; TT, triple therapy (VKA + DAPT); DT, dual therapy (OAC + SAPT); VKA, vitamin K antagonist; OAC, oral anticoagulation (VKA or NOAC); NOAC, non vitamin K oral anticoagulant; DAPT, dual antiplatelet therapy (aspirin + P2Y12 inhibitor); SAPT, single antiplatelet therapy; and P2Y12i, P2Y12 inhibitor.

cause death, stent thrombosis, or MI between the NOAC $+\mathrm{P}^{2} \mathrm{Y}_{12}$ inhibitor, VKA + SAPT, and VKA + DAPT treatments (Table II). The evidence derived from direct or indirect comparisons was due to the open loop of 3 strategies, explaining the lack of inconsistencies. The funnel plot revealed a low publication bias with the absence of small-study effects (Figure 3).

Subgroup network meta-analysis of VKA + DAPT, VKA + Aspirin, VKA + Clopidogrel, and NOAC + P2Y $_{12}$ inhibitor: Eleven studies ${ }^{8,9,12,14,15,17,18,20-23)}$ were included in the network meta-analysis of this subgroup analysis, and the network plot is presented in Figure 1B. The contribution plot and funnel plot are presented in Supplemental Figures 3 and 4, respectively. VKA + DAPT was the worst antithrombotic strategy given that it exhibited the highest risk of major bleeding among these strategies $\left(\mathrm{NOAC}+\mathrm{P} 2 \mathrm{Y}_{12}\right.$ inhibitor, OR: 1.69, 95\% CI: 1.322.17; VKA + Clopidogrel, OR: 1.47, 95\% CI: 1.17-1.84; VKA + Aspirin, OR: 1.55, 95\% CI: 1.29-1.88; Table III and Supplemental Figure 5). Of note, VKA + Aspirin exhibited a similar risk of major bleeding compared with VKA + Clopidogrel (OR: 0.94, 95\% CI: 0.73-1.23) but was associated with increased risks of ischaemic stroke (OR: 2.10, 95\% CI: 1.33-3.32) and all-cause death (OR: 1.77, 95\% CI: 1.15-2.74) versus VKA + Clopidogrel. Moreover, $\mathrm{NOAC}+\mathrm{P}_{2} \mathrm{Y}_{12}$ inhibitor could reduce the risk of major bleeding compared with VKA + DAPT (OR: 0.59 , 95\% CI: 0.46-0.76) with similar risks of MACE, ischaemic stroke, all-cause death, stent thrombosis, and MI compared with VKA + DAPT and VKA + Clopidogrel (Table III). The inconsistency could not be calculated given that no triangular or quadratic loops were found.

\section{Discussion}

To the best of our knowledge, this is the first network meta-analysis to explore the effects of NOAC + $\mathrm{P}_{2} \mathrm{Y}_{12}$ inhibitor, VKA + Aspirin/Clopidogrel, and VKA + DAPT in AF patients with PCI. The major new findings were as follows: (1) NOAC $+\mathrm{P} 2 \mathrm{Y}_{12}$ inhibitor ranked first regarding the reduced risk of major bleeding without the increased risk of thrombotic events compared with the recommended VKA-based triple therapy; (2) subgroup analysis revealed that VKA + Aspirin exhibited increased risks of ischaemic stroke and all-cause death compared with VKA + Clopidogrel, challenging the similar recommendation levels of VKA + Aspirin and VKA + Clopidogrel in the current guidelines; and (3) VKA-based triple therapy ranked last due to the highest risk of major bleeding without a reduced risk of thrombotic events compared with dual therapy, indicating that triple therapy might be replaced by $\mathrm{NOAC}+\mathrm{P}_{2} \mathrm{Y}_{12}$ inhibitor or VKA + Clopido- 
A

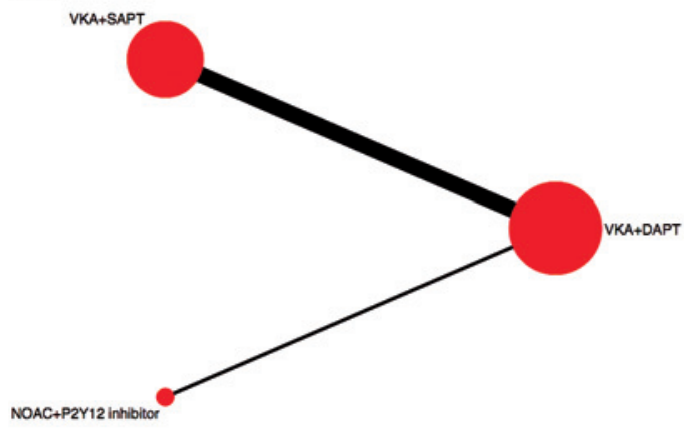

B

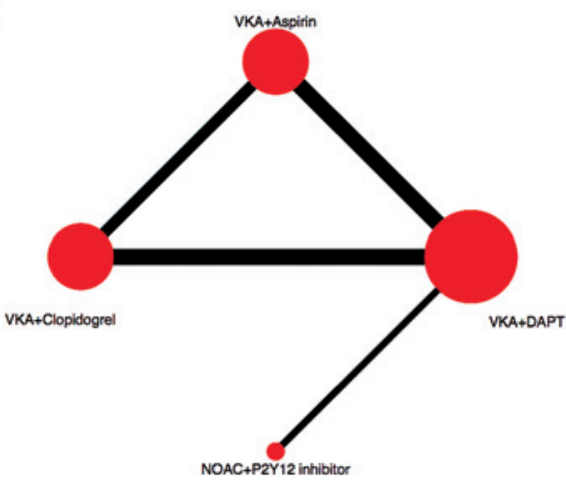

Figure 1. Network plot of available antithrombotic strategies. A: Network plot of VKA + DAPT, VKA + SAPT, and NOAC $+\mathrm{P}_{12} \mathrm{Y}_{12}$ inhibitor. B: Network plot of VKA + DAPT, VKA + Aspirin, VKA + Clopidogrel, and NOAC + P2 $\mathrm{Y}_{12}$ inhibitor. The size of nodes reflects the number of studies in each treatment, and the thickness of lines reflects the number of direct comparisons in studies. VKA indicates vitamin K antagonist; DAPT, dual antiplatelet therapy; NOAC, non-vitamin K oral anticoagulants; and SAPT, single antiplatelet therapy.

Table II. Main Analysis of Effect of Antithrombotic Strategies for Primary and Secondary Endpoints

\begin{tabular}{|c|c|c|c|}
\hline & $\begin{array}{c}\mathrm{NOAC}+\mathrm{P} 2 \mathrm{Y} 12 \\
\text { inhibitor }\end{array}$ & $\mathrm{VKA}+\mathrm{SAPT}$ & VKA + DAPT \\
\hline \multicolumn{4}{|l|}{ Major bleeding } \\
\hline NOAC + P2Y12 inhibitor & - & $1.18(0.86,1.62)$ & $1.75(1.33,2.30)$ \\
\hline $\mathrm{VKA}+\mathrm{SAPT}$ & $0.85(0.62,1.16)$ & - & $1.48(1.27,1.72)$ \\
\hline VKA + DAPT & $0.57(0.43,0.75)$ & $0.68(0.58,0.79)$ & - \\
\hline \multicolumn{4}{|l|}{ MACE } \\
\hline $\mathrm{NOAC}+\mathrm{P} 2 \mathrm{Y} 12$ inhibitor & - & $0.89(0.56,1.40)$ & $0.94(0.64,1.38)$ \\
\hline $\mathrm{VKA}+\mathrm{SAPT}$ & $1.13(0.72,1.77)$ & - & $1.06(0.83,1.36)$ \\
\hline VKA + DAPT & $1.06(0.73,1.55)$ & $0.94(0.74,1.21)$ & - \\
\hline \multicolumn{4}{|l|}{ Ischemic stroke } \\
\hline NOAC + P2Y12 inhibitor & - & $0.97(0.55,1.72)$ & $0.82(0.50,1.36)$ \\
\hline $\mathrm{VKA}+\mathrm{SAPT}$ & $1.03(0.58,1.82)$ & - & $0.85(0.65,1.10)$ \\
\hline $\mathrm{VKA}+\mathrm{DAPT}$ & $1.22(0.74,2.02)$ & $1.18(0.91,1.54)$ & - \\
\hline \multicolumn{4}{|l|}{ All cause death } \\
\hline NOAC + P2Y12 inhibitor & - & $1.10(0.66,1.85)$ & $0.93(0.62,1.40)$ \\
\hline $\mathrm{VKA}+\mathrm{SAPT}$ & $0.91(0.54,1.52)$ & - & $0.85(0.62,1.15)$ \\
\hline VKA + DAPT & $1.07(0.71,1.61)$ & $1.18(0.87,1.61)$ & - \\
\hline \multicolumn{4}{|l|}{ Stent thrombosis } \\
\hline NOAC + P2Y12 inhibitor & - & $0.93(0.41,2.10)$ & $0.71(0.39,1.29)$ \\
\hline $\mathrm{VKA}+\mathrm{SAPT}$ & $1.08(0.48,2.43)$ & - & $0.76(0.44,1.30)$ \\
\hline VKA + DAPT & $1.42(0.77,2.59)$ & $1.32(0.77,2.26)$ & - \\
\hline \multicolumn{4}{|l|}{ Myocardial Infarction } \\
\hline $\mathrm{NOAC}+\mathrm{P} 2 \mathrm{Y} 12$ inhibitor & - & $0.95(0.56,1.61)$ & $0.80(0.59,1.10)$ \\
\hline VKA + SAPT & $1.05(0.62,1.77)$ & - & $0.84(0.56,1.28)$ \\
\hline VKA + DAPT & $1.24(0.91,1.71)$ & $1.18(0.78,1.80)$ & - \\
\hline
\end{tabular}

VKA indicates vitamin $\mathrm{K}$ antagonist; NOAC, non vitamin $\mathrm{K}$ oral anticoagulant; DAPT, dual antiplatelet therapy (aspirin + P2Y12 inhibitor); SAPT, single antiplatelet therapy; and MACE, major adverse cardiovascular events.

grel in AF patients following PCI.

DAPT therapy is the cornerstone treatment for patients undergoing coronary stents, and $\mathrm{OAC}$ is an effective strategy to prevent thromboembolic events in AF patients with a $\mathrm{CHA}_{2} \mathrm{DS}_{2}-\mathrm{VASc}$ score $\geq 2$. Greater than $10 \%$ of PCI patients have concomitant $\mathrm{AF}$, requiring VKA plus DAPT in theory to simultaneously reduce the risk of ischaemic stroke and stent thrombosis. This VKA-based triple therapy has been strongly recommended for AF pa- tients after PCI in current guidelines ${ }^{5,6)}$ but was blamed for the unacceptably high bleeding risk over the past decade. Bleeding complications have been the Achilles' heel of VKA-based triple therapy with incidences of up to 26$44 \%$ per year in recent RCTs with strict control of the international normalized ratio (INR). ${ }^{8,9,14)}$ This finding might explain why only $35.7 \%$ of AF patients after PCI are prescribed VKA-based triple therapy in real-word clinical practice $^{25)}$ despite the strong recommendations by current 


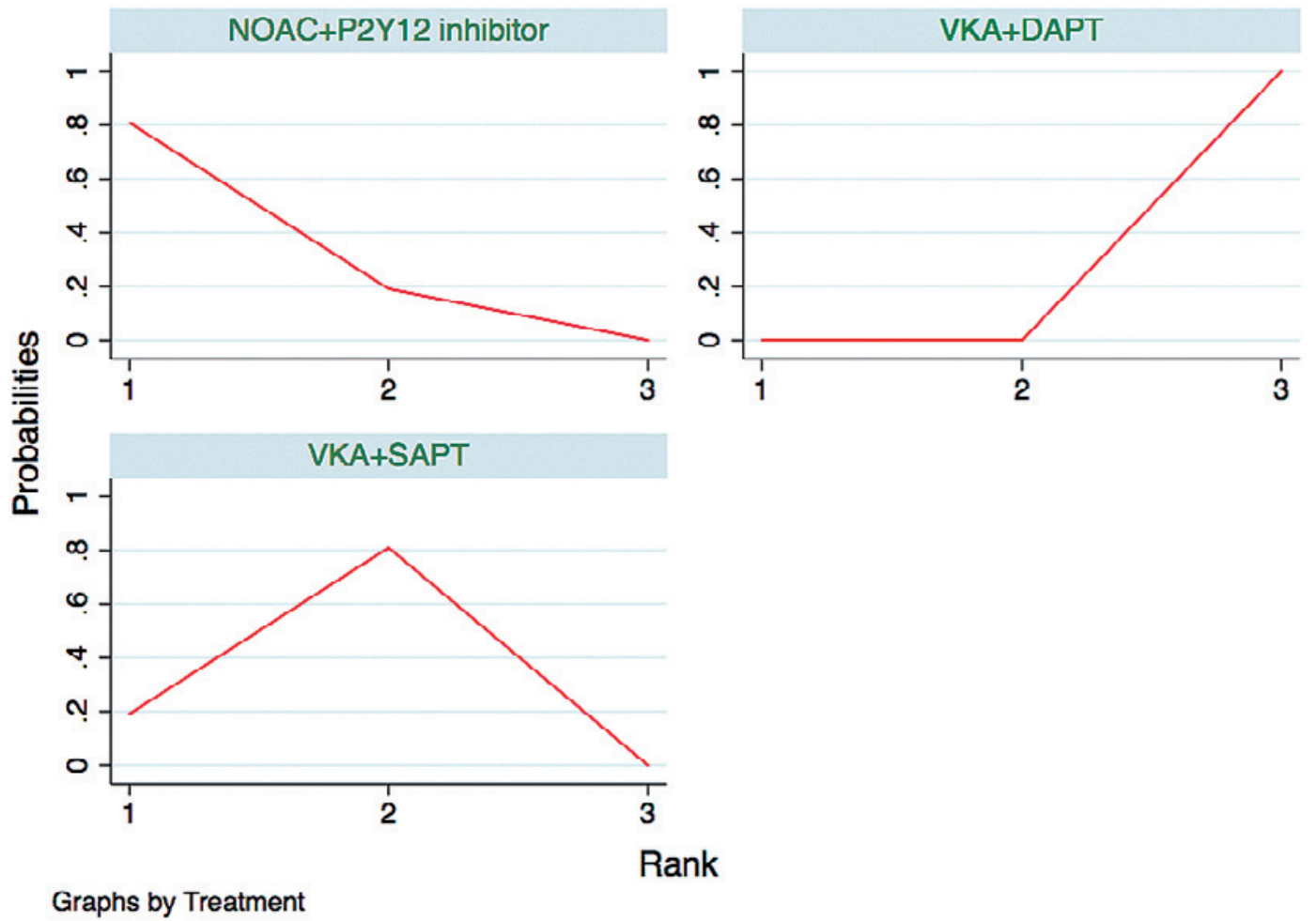

Figure 2. Rankogram of available antithrombotic strategies for major bleeding. VKA indicates vitamin K antagonist; DAPT, dual antiplatelet therapy; NOAC, nonvitamin K oral anticoagulants; and SAPT, single antiplatelet therapy.

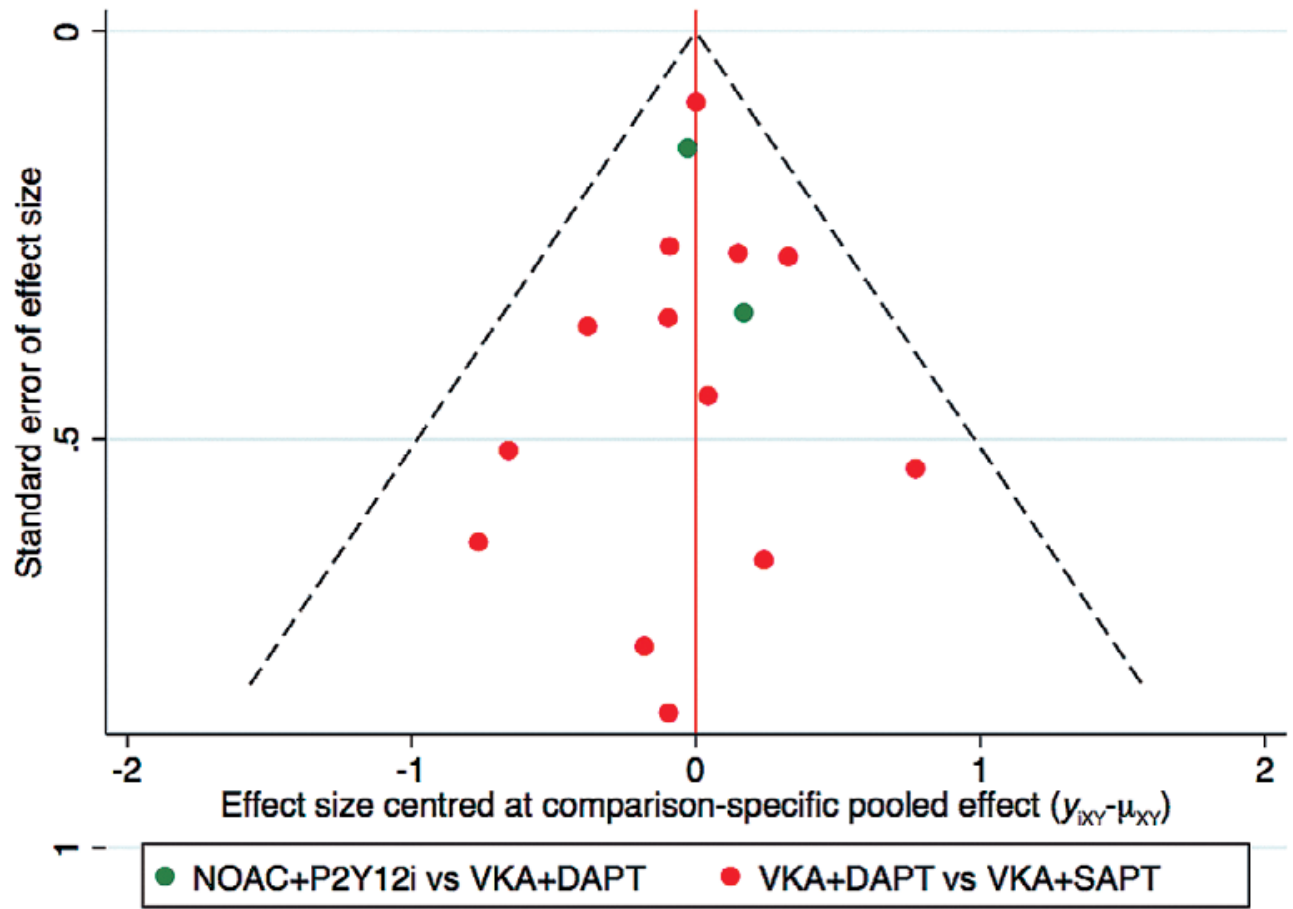

Figure 3. Funnel plot for assessing publication bias. VKA indicates vitamin K antagonist; DAPT, dual antiplatelet therapy; NOAC, non-vitamin K oral anticoagulants; SAPT, single antiplatelet therapy. 
Table III. Sub-Study Analysis of Effect of Antithrombotic Strategies for Primary and Secondary Endpoints

\begin{tabular}{|c|c|c|c|c|}
\hline & $\begin{array}{c}\mathrm{NOAC}+\mathrm{P} 2 \mathrm{Y} 12 \\
\text { inhibitor }\end{array}$ & VKA + Clopidogrel & VKA + Aspirin & $\mathrm{VKA}+\mathrm{DAPT}$ \\
\hline \multicolumn{5}{|l|}{ Major bleeding } \\
\hline NOAC + P2Y12 inhibitor & - & $1.16(0.82,1.62)$ & $1.09(0.80,1.49)$ & $1.69(1.32,2.17)$ \\
\hline VKA + Clopidogrel & $0.87(0.62,1.21)$ & - & $0.94(0.73,1.23)$ & $1.47(1.17,1.84)$ \\
\hline VKA + Aspirin & $0.92(0.67,1.25)$ & $1.06(0.81,1.38)$ & - & $1.55(1.29,1.88)$ \\
\hline VKA + DAPT & $0.59(0.46,0.76)$ & $0.68(0.54,0.86)$ & $0.64(0.53,0.78)$ & - \\
\hline \multicolumn{5}{|l|}{ MACE } \\
\hline NOAC + P2Y12 inhibitor & - & $0.77(0.43,1.38)$ & $1.00(0.55,1.83)$ & $0.94(0.60,1.48)$ \\
\hline VKA + Clopidogrel & $1.30(0.72,2.34)$ & - & $1.31(0.85,2.01)$ & $1.22(0.85,1.77)$ \\
\hline VKA + Aspirin & $1.00(0.55,1.82)$ & $0.77(0.50,1.18)$ & - & $0.94(0.64,1.38)$ \\
\hline VKA + DAPT & $1.06(0.67,1.68)$ & $0.82(0.57,1.18)$ & $1.07(0.72,1.57)$ & - \\
\hline \multicolumn{5}{|l|}{ Ischemic stroke } \\
\hline NOAC + P2Y12 inhibitor & - & $0.57(0.29,1.12)$ & $1.20(0.67,2.15)$ & $0.82(0.50,1.36)$ \\
\hline VKA + Clopidogrel & $1.74(0.89,3.41)$ & - & $2.10(1.33,3.32)$ & $1.43(0.92,2.23)$ \\
\hline VKA + Aspirin & $0.83(0.46,1.49)$ & $0.48(0.30,0.75)$ & - & $0.68(0.51,0.91)$ \\
\hline VKA + DAPT & $1.22(0.74,2.02)$ & $0.70(0.45,1.09)$ & $1.47(1.10,1.96)$ & - \\
\hline \multicolumn{5}{|l|}{ All cause death } \\
\hline NOAC + P2Y12 inhibitor & - & $0.78(0.45,1.37)$ & $1.39(0.77,2.51)$ & $0.93(0.61,1.43)$ \\
\hline VKA + Clopidogrel & $1.28(0.73,2.24)$ & - & $1.77(1.15,2.74)$ & $1.19(0.83,1.70)$ \\
\hline VKA + Aspirin & $0.72(0.40,1.31)$ & $0.56(0.36,0.87)$ & - & $0.67(0.45,1.01)$ \\
\hline VKA + DAPT & $1.07(0.70,1.65)$ & $0.84(0.59,1.20)$ & $1.49(0.99,2.23)$ & - \\
\hline \multicolumn{5}{|l|}{ Stent thrombosis } \\
\hline NOAC + P2Y12 inhibitor & - & $0.63(0.21,1.90)$ & $1.72(0.50,5.93)$ & $0.72(0.35,1.48)$ \\
\hline VKA + Clopidogrel & $1.60(0.53,4.85)$ & - & $2.74(0.80,9.45)$ & $1.15(0.50,2.67)$ \\
\hline VKA + Aspirin & $0.58(0.17,2.01)$ & $0.36(0.11,1.26)$ & - & $0.42(0.15,1.16)$ \\
\hline VKA + DAPT & $1.39(0.68,2.85)$ & $0.87(0.38,2.02)$ & $2.39(0.86,6.60)$ & - \\
\hline \multicolumn{5}{|l|}{ Myocardial Infarction } \\
\hline $\mathrm{NOAC}+\mathrm{P} 2 \mathrm{Y} 12$ inhibitor & - & $0.79(0.43,1.44)$ & $1.35(0.58,3.17)$ & $0.80(0.59,1.10)$ \\
\hline VKA + Clopidogrel & $1.27(0.69,2.33)$ & - & $1.72(0.73,4.07)$ & $1.02(0.61,1.71)$ \\
\hline VKA + Aspirin & $0.74(0.32,1.73)$ & $0.58(0.25,1.37)$ & - & $0.59(0.27,1.31)$ \\
\hline VKA + DAPT & $1.24(0.91,1.71)$ & $0.98(0.58,1.64)$ & $1.68(0.76,3.71)$ & - \\
\hline
\end{tabular}

VKA indicates vitamin $\mathrm{K}$ antagonist; NOAC, non vitamin $\mathrm{K}$ oral anticoagulant; DAPT, dual antiplatelet therapy (aspirin + P2Y12 inhibitor); SAPT, single antiplatelet therapy; and MACE, major adverse cardiovascular events.

guidelines. In fact, this recommendation has only been supported by observational studies or subgroup analyses of RCTs, ${ }^{5,6,26)}$ and recently, several $\mathrm{RCTs}^{8,9,14)}$ and metaanalyses $^{3,4)}$ have demonstrated that OAC plus clopidogrel is superior to triple therapy with a reduced risk of bleeding complications without an increased risk of thromboembolic events. Therefore, the safety and efficacy of VKA-based triple therapy should be re-evaluated, and the regimen might not be suitable for the majority of $\mathrm{AF}$ patients undergoing PCI along with coronary device development in the present era.

The use of NOAC has rapidly increased in recent years $^{25}$ given the lack of a need for frequent monitoring of INR. Prevention of Bleeding in Patients with Atrial Fibrillation Undergoing PCI (PIONEER AF-PCI), ${ }^{9)}$ which enrolled 2,725 patients with AF who underwent PCI, revealed that rivaroxaban (15 mg once daily) plus a $\mathrm{P} 2 \mathrm{Y}_{12}$ inhibitor (clopidogrel: 94.4\%) was associated with a reduced rate of clinically significant bleeding compared with VKA-based triple therapy with similar efficacy rates. Similarly, dabigatran (either $110 \mathrm{mg}$ or $150 \mathrm{mg}$ twice daily) plus a $\mathrm{P} 2 \mathrm{Y}_{12}$ inhibitor (clopidogrel: approximately $88 \%$ ) resulted in a reduction in major bleeding events and similar thromboembolic events compared with triple therapy in the RE-DUAL PCI study (Dual Antithrombotic
Therapy with Dabigatran after PCI in Atrial Fibrillation). ${ }^{8)}$ Moreover, two on-going RCTs will assess the safety and efficacy of other NOACs (apixaban and edoxaban) plus a $\mathrm{P}_{2} \mathrm{Y}_{12}$ inhibitor in AF patients receiving PCI (Clinical trial identifiers: NCT02415400 and NCT02866175). In summary, these results confirmed that the combination of NOAC and a $\mathrm{P} 2 \mathrm{Y}_{12}$ inhibitor could reduce bleeding complications compared with triple therapy, and the patient level meta-analysis of these 4 RCTs will provide more powerful data to illustrate the efficacy of NOAC-based dual therapy.

Current guidelines recommend that dual therapy with $\mathrm{OAC}$ and aspirin or clopidogrel should be considered to prevent recurrent coronary and cerebral ischaemic events. Aspirin and clopidogrel have a similar status in the guidelines, and it is reasonable to prescribe OAC plus aspirin or clopidogrel for these patients. However, our network meta-analysis demonstrates that the risk of OAC plus aspirin for AF patients undergoing PCI can increase the risk of ischaemic stroke by $110 \%$ and all-cause death by $77 \%$ with increasing trends of MI, stent thrombosis, and MACE compared with OAC plus clopidogrel, which is consistent with the findings of previous studies. ${ }^{17,18)}$ In addition, the CAPRIE (Clopidogrel Versus Aspirin in $\mathrm{Pa}-$ tients at Risk of Ischemic Events) study, ${ }^{27}$ including 
19,185 patients with atherosclerotic vascular disease, demonstrated that clopidogrel ( $75 \mathrm{mg}$ once daily) is more effective than aspirin (325 $\mathrm{mg}$ once daily) in reducing the combined risk of ischaemic stroke, MI, and vascular death. Of note, OAC plus clopidogrel exhibited a similar major bleeding risk compared with OAC plus aspirin. Hence, the optimal antithrombotic strategy for AF patients undergoing PCI is OAC combined with clopidogrel, not aspirin.

Several questions remain unanswered. First, individualized antithrombotic strategies should be chosen according to $\mathrm{CHA}_{2} \mathrm{DS}_{2}$-VASc and HAS-BLED scores to balance the benefit and risk. However, there is no consensus regarding the selection of the best strategy based on the different levels of risk scores. Second, in our dataset, only one RCT (ISAR-TRIPLE: Intracoronary Stenting and Antithrombotic Regimen-Testing of a 6-Week Versus a 6Month Clopidogrel Treatment Regimen in Patients With Concomitant Aspirin and Oral Anticoagulant Therapy Following Drug-Eluting Stenting) explored the net clinical outcomes of 6 weeks of triple therapy, ${ }^{15)}$ and the optimal duration of triple therapy or dual therapy in patients with newer generation stents or complex coronary lesions remains unclear. Third, new $\mathrm{P}_{2} \mathrm{Y}_{12}$ inhibitors, such as ticagrelor and prasugrel, ${ }^{28,29)}$ reduce the risk of cardiac death and stent thrombosis compared with clopidogrel at the cost of increased minor bleeding complications. We still do not know whether OAC plus ticagrelor is superior to traditional VKA-based triple therapy for patients with high ischaemic risk.

The present study has several limitations. First, it is not a patient-level meta-analysis, which prevents additional subgroup analyses. Second, the duration of VKAbased triple therapy and the baseline patient characteristics were slightly different across the included studies, but funnel plots of both main and subgroup analyses only reveal low publication bias. Third, minimal bias can occur due to the exclusion of the DAPT regimen for AF patients after PCI, but a number of studies and meta-analyses have demonstrated that DAPT with the omission of OAC increases the risk of thrombotic events. ${ }^{3,4,7,18)}$ Finally, our findings were derived from a network meta-analysis with direct or indirect comparisons and not large-scale head-tohead RCTs, so these findings should be cautiously reported and applied.

\section{Conclusions}

In patients with $\mathrm{AF}$ undergoing PCI, NOAC plus $\mathrm{P} 2 \mathrm{Y}_{12}$ inhibitor and VKA plus clopidogrel, but not VKA plus aspirin, were associated with reduced risks of major bleeding compared with recommended VKA-based triple therapy, whereas the rates of thrombotic events were similar.

\section{Disclosures}

Conflicts of interest: The authors declare they have no potential conflicts of interest with respect to the research, authorship, and/or publication of this article.

\section{References}

1. Hwang KK, Eom SY, Lee SY, et al. Atrial fibrillation on admission is related with higher mortality in ST-segment elevation myocardial infarction patients. Int Heart J 2017; 58: 486-94.

2. Gayed M, Yadak N, Qamhia W, et al. Comorbidities and complications in nonagenarians undergoing coronary angiography and intervention. Int Heart J 2017; 58: 180-4.

3. Chaudhary N, Bundhun PK, Yan H. Comparing the clinical outcomes in patients with atrial fibrillation receiving dual antiplatelet therapy and patients receiving an addition of an anticoagulant after coronary stent implantation: A systematic review and meta-analysis of observational studies. Medicine (Baltimore) 2016; 95: e5581.

4. Gao XF, Chen Y, Fan ZG, et al. Antithrombotic regimens for patients taking oral anticoagulation after coronary intervention: A meta-analysis of 16 clinical trials and 9,185 patients. Clin Cardiol 2015; 38: 499-509.

5. Kirchhof P, Benussi S, Kotecha D, et al. 2016 ESC guidelines for the management of atrial fibrillation developed in collaboration with EACTS. Eur Heart J 2016; 37: 2893-962.

6. Valgimigli M, Bueno H, Byrne RA, et al. 2017 ESC focused update on dual antiplatelet therapy in coronary artery disease developed in collaboration with EACTS: The Task Force for dual antiplatelet therapy in coronary artery disease of the European Society of Cardiology (ESC) and of the European Association for Cardio-Thoracic Surgery (EACTS). Eur Heart J 2018; 39: 213-60.

7. Cavallari I, Patti G. Meta-analysis comparing the safety and efficacy of dual versus triple antithrombotic therapy in patients with atrial fibrillation undergoing percutaneous coronary intervention. Am J Cardiol 2018; 121: 718-24.

8. Cannon CP, Bhatt DL, Oldgren J, et al. Dual antithrombotic therapy with dabigatran after PCI in atrial fibrillation. N Engl J Med 2017; 377: 1513-24.

9. Gibson CM, Mehran R, Bode C, et al. Prevention of bleeding in patients with atrial fibrillation undergoing PCI. N Engl J Med 2016; 375: 2423-34.

10. Chaimani A, Higgins JP, Mavridis D, et al. Graphical tools for network meta-analysis in STATA. PLoS One 2013; 8: e76654.

11. White IR, Barrett JK, Jackson D, et al. Consistency and inconsistency in network meta-analysis: model estimation using multivariate meta-regression. Res Synth Methods 2012; 3: 111-25.

12. Batra G, Friberg L, Erlinge D, et al. Antithrombotic therapy after myocardial infarction in patients with atrial fibrillation undergoing percutaneous coronary intervention. Eur Heart J Cardiovasc Pharmacother 2018; 4: 36-45.

13. De Vecchis R, Cantatrione C, Mazzei D. Clinical relevance of anticoagulation and dual antiplatelet therapy to the outcomes of patients with atrial fibrillation and recent percutaneous coronary intervention with stent. J Clin Med Res 2016; 8: 153-61.

14. Dewilde WJ, Oirbans T, Verheugt FW, et al. Use of clopidogrel with or without aspirin in patients taking oral anticoagulant therapy and undergoing percutaneous coronary intervention: an open-label, randomised, controlled trial. Lancet 2013; 381: 1107-15.

15. Fiedler KA, Maeng M, Mehilli J, et al. Duration of triple therapy in patients requiring oral anticoagulation after drug-eluting stent implantation: The ISAR-TRIPLE Trial. J Am Coll Cardiol 2015; 65: 1619-29.

16. Gao F, Zhou YJ, Wang ZJ, et al. Comparison of different antithrombotic regimens for patients with atrial fibrillation undergoing drug-eluting stent implantation. Circ J 2010; 74: 701-8.

17. Karjalainen PP, Porela P, Ylitalo A, et al. Safety and efficacy of combined antiplatelet-warfarin therapy after coronary stenting. Eur Heart J 2007; 28: 726-32.

18. Lamberts M, Gislason GH, Olesen JB, et al. Oral anticoagulation and antiplatelets in atrial fibrillation patients after myocardial infarction and coronary intervention. J Am Coll Cardiol 2013; 62: 981-9. 
19. Lopes RD, Rao M, Simon DN, et al. Triple vs dual antithrombotic therapy in patients with atrial fibrillation and coronary artery disease. Am J Med 2016; 129: 592-599.e591.

20. Nguyen MC, Lim YL, Walton A, et al. Combining warfarin and antiplatelet therapy after coronary stenting in the global registry of acute coronary events: is it safe and effective to use just one antiplatelet agent? Eur Heart J 2007; 28: 1717-22.

21. Persson J, Lindback J, Hofman-Bang C, et al. Efficacy and safety of clopidogrel after PCI with stenting in patients on oral anticoagulants with acute coronary syndrome. EuroIntervention 2011; 6: 1046-52.

22. Rubboli A, Magnavacchi P, Guastaroba P, et al. Antithrombotic management and 1-year outcome of patients on oral anticoagulation undergoing coronary stent implantation (from the Registro Regionale Angioplastiche Emilia-Romagna Registry). Am J Cardiol 2012; 109: 1411-7.

23. Rubboli A, Schlitt A, Kiviniemi T, et al. One-year outcome of patients with atrial fibrillation undergoing coronary artery stenting: an analysis of the AFCAS registry. Clin Cardiol 2014; 37 : 357-64.

24. Sambola A, Ferreira-Gonzalez I, Angel J, et al. Therapeutic strategies after coronary stenting in chronically anticoagulated patients: the MUSICA study. Heart 2009; 95: 1483-8.
25. Sindet-Pedersen C, Staerk L, Lamberts M, et al. Use of oral anticoagulants in combination with antiplatelet(s) in atrial fibrillation. Heart 2018; 104: 912-20.

26. Amano H, Saito D, Yabe T, et al. Efficacy and safety of triple therapy and dual therapy with direct oral anticoagulants compared to warfarin. Int Heart J 2017; 58: 570-6.

27. Committee CS. A randomised, blinded, trial of clopidogrel versus aspirin in patients at risk of ischaemic events (CAPRIE). CAPRIE Steering Committee. Lancet 1996; 348: 1329-39.

28. Wallentin L, Becker RC, Budaj A, et al. Ticagrelor versus clopidogrel in patients with acute coronary syndromes. N Engl J Med 2009; 361: 1045-57.

29. Wiviott SD, Braunwald E, McCabe $\mathrm{CH}$, et al. Prasugrel versus clopidogrel in patients with acute coronary syndromes. N Engl J Med 2007; 357: 2001-15.

\section{Supplemental Files}

Supplementary Figures 1-5

Supplemental Tables I, II

Please see supplemental files; https://doi.org/10.1536/ihj.18-464 